\title{
Reproducible Pyrolysis-Gas Chromatography of Micro-organisms with Solid Stationary Phases and Isothermal Oven Temperatures
}

\author{
By G. L. FRENCH,* I. PHILLIPS AND S. CHINN \\ Departments of Microbiology and Community Medicine, St Thomas's Hospital Medical \\ School, London SE1 7EH, U.K.
}

(Received 3 December 1980; revised 29 January 1981)

\begin{abstract}
Eight solid stationary phases were examined for their suitability for pyrolysis-gas chromatography (Py-GC) of micro-organisms. With temperature programming these phases offered little advantage over the traditional liquid phase Carbowax 20M, but at an isothermal analysis temperature of $100^{\circ} \mathrm{C}$ their use solved many technical problems. Pyrograms were produced containing small numbers of baseline-resolved peaks which eluted within 8 to $25 \mathrm{~min}$. Four to six specimens per hour could be examined with two pyrolysers attached to one chromatograph oven. When a control organism was used to derive normalized results, pyrograms were reproducible with a second column and a second pyrolyser, suggesting that inter-laboratory reproducibility may be possible.

Five different bacterial genera were well discriminated and some differentiation was achieved between different isolates of Streptococcus mutans, but similarity between pyrograms was unrelated to orthodox taxonomic grouping. The best discrimination was achieved with Chromosorb 104, followed by Chromosorb 101 and Tenax-GC. With solid phases and isothermal oven temperatures Py-GC is a promising technique for microbial identification.
\end{abstract}

\section{INTRODUCTION}

Pyrolysis-gas chromatography (Py-GC) has been used for many years for the identification and classification of micro-organisms (Gutteridge \& Norris, 1979). However, technical difficulties have prevented this method from being used for routine microbial identification, and inter-laboratory reproducibility has never been achieved. The majority of previous studies have used the polar liquid stationary phase Carbowax 20M, and our own experience has highlighted the problems associated with this material, which include poor baseline resolution, rapid column deterioration, long analysis times and failure to reproduce pyrograms from control organisms on new columns (French et al., 1980).

Carbowax $20 \mathrm{M}$ is capable of separating only some of the products of bacterial pyrolysis, and there is no theoretical reason why other phases should not be used (Gutteridge \& Norris, 1979). Needleman \& Stuchberý (1977), for example, produced a similar number of pyrogram peaks from the pyrolysis of coliforms with both polar (Carbowax 20M) and non-polar (Apiezon L) stationary phases.

Chemists have used Py-GC for the analysis of polymers such as paints and plastics. May et al. (1973) found that the solid phase Poropak Q, which consists of cross-linked polystyrene beads, gave the most reproducible results. They commented: 'an important reason for choosing the polymer bead packing Poropak $Q$ is that it can be used without preparation ..., (it) has a long life ..., (and) reproducibility from column to column is ... mainly dependent on the manufacturer's quality control'. 
A variety of solid phases are available, each with different separation characteristics (Hollis, 1966). We have investigated several of these phases for use in bacterial Py-GC, with both programmed and isothermal oven temperatures. Since different strains of the same bacterial species may give different pyrograms (Reiner \& Ewing, 1968; Sekhon \& Carmichael, 1975; Brosseau \& Carmichael, 1978; French et al., 1980), the chromatographic systems were tested for reproducibility and discrimination by the replicate pyrolysis of single strains from each of five different genera. Several isolates of Streptococcus mutans were also examined to test for bacterial identification and intra-species differentiation.

\section{METHODS}

Organisms. Five organisms were examined to test for discrimination and reproducibility: Escherichia coli NCTC 10418, Pseudomonas aeruginosa NCTC 10622, Klebsiella aerogenes NCTC 10896, Staphylococcus aureus NCTC 6571 and Streptococcus mutans 206 (a clinical isolate from St Thomas' Hospital). Nine further isolates of Strep. mutans from clinical sources or received from reference laboratories were used to test for intra-species differentiation. All organisms were grown overnight at $37^{\circ} \mathrm{C}$ in an atmosphere of $10 \% \mathrm{CO}_{2}$ in air on bacterial filters (Millipore type HA, pore size $0.45 \mu \mathrm{m}$ ) placed on the surface of $5 \%$ horse blood agar plates (Columbia blood agar, Oxoid CM331) (Oxborrow et al., 1976, 1977a, 1977 b).

Pyrolysis. Two Curie-point pyrolyser/gas chromatography instruments were used: the Pye 104 and the Pye 204 (Pye Unicam, Cambridge, U.K.). Small amounts (less than $100 \mu \mathrm{g}$ ) of bacterial cells were transferred to the terminal $3 \mathrm{~mm}$ of flame-cleaned iron wires and pyrolysed for $7.5 \mathrm{~s}$ (Pye 104) or $8 \mathrm{~s}$ (Pye 204) at $770^{\circ} \mathrm{C}$. Wires were changed daily rather than after each pyrolysis. This reduced the incidence of septum leakage without loss of pyrogram reproducibility. Disposable quartz tubes which sheathed the wires were changed after each pyrolysis (Pye 204) or weekly (Pye 104).

Stationary phases. Eight polymer solid phases were examined: Tenax-GC (mesh size 60-80), Poropak Q $(80-100)$, and the Chromosorb series of porous polymers 101 (80-100), $102(100-120), 103(100-120), 104$ $(100-120), 105(100-120)$ and $106(60-80)$ (Phase Separations Ltd, Queensferry, Clwyd, U.K.). The liquid phase $5 \%$ Carbowax 20M TPA on Gas Chrom Q (100-120 mesh) was also tested.

Gas chromatography. Packed glass columns $1.5 \mathrm{~m} \times 4 \mathrm{~mm}$ i.d. were connected to flame ionization detectors. The carrier gas was nitrogen. Flow rates for optimal peak separations were $15 \mathrm{ml} \mathrm{min}^{-1}$ for Tenax-GC and $40 \mathrm{ml} \mathrm{min}^{-1}$ for all other phases. For temperature-programmed analysis the oven temperature was held at $75^{\circ} \mathrm{C}$ for $2 \mathrm{~min}$ from the start of pyrolysis, programmed with a $6^{\circ} \mathrm{C} \mathrm{min}^{-1}$ rise to 200 or $250^{\circ} \mathrm{C}$, and then held at this temperature to the end of the analysis. For isothermal analysis the oven and inlet temperatures were held at $100^{\circ} \mathrm{C}$. The detector temperature was $250^{\circ} \mathrm{C}$.

Area measurement and normalization. A Hewlett-Packard 3385A electronic integrator received the detector signals unattenuated (Pye 104) or at an attenuation of $1 \times 8$ (Pye 204). Peak areas were measured from a horizontal baseline set at the start of the pyrogram and peaks were integrated by dropping perpendiculars to this line at each valley. When adjacent peaks were irregularly resolved, peak areas were summed to give a reproducible value for the peak group. Peak areas were expressed as a percentage of the total area of all peaks, thus correcting for differences in sample size. The first peak of each pyrogram was used as the reference for retention time correction which was performed automatically by the integrator with a retention time 'window' of $10 \%$.

Each day a fresh culture of Strep. mutans 206 was pyrolysed as a control. Results from this control run were used to calculate response factors to standardize the peak area percentage values. The response factor (RF) for a peak $\mathrm{Y}$ is given by

$$
R F_{Y}=\frac{\text { Expected amount of } Y(\text { as area percentage) }}{\text { Actual area of } Y \text { (as integrator counts) }}
$$

The response factor for each peak was entered as the mean of the previously established factors and the new factor derived that day. An area percentage normalization procedure was then applied to peak values obtained in subsequent analyses. The normalized area percentage of a peak $Y$ is given by

$$
\text { Normalized } \% \mathrm{Y}=\frac{(\text { Area } \mathrm{Y}) \times(\text { Response factor } \mathrm{Y})}{\Sigma(\text { Area } \times \text { Response factor for all peaks })} \times 100
$$

These calculations were performed automatically by the integrator. 
Reproducibility between columns and between pyrolysers. To investigate the effect of changing columns and pyrolysers, a second column was packed with a new batch of Chromosorb 103 and connected to the first pyrolyser of the Pye 204. The original Chromosorb 103 column was attached to a second Pye 204 pyrolyser in the same chromatograph oven, and the five test organisms were again analysed five times with each column.

Statistical analysis. Linear discriminant (canonical variates) analysis was used to calculate functions of the normalized area percentages to separate the different bacterial genera (Healy, 1973; MacFie et al., 1978). Generalized (Mahalanobis) distances between the groups were calculated as a measure of total discrimination, and the separation achieved by the first two discriminant functions was displayed by plotting the data and drawing $95 \%$ tolerance circles in the plane defined by these two functions.

The discriminant analyses were carried out on the University of London's CDC6600 computer. A specially written program produced a graphical output via the computing centre's microfilm facility. Some analyses were also performed using the subprogram Discriminant from the Statistical Package for the Social Sciences (SPSS) (Nie et al., 1975).

The discriminant functions obtained from the original Chromosorb 103 column with the first pyrolyser were applied to the data obtained with the second column, and to those obtained with the second pyrolyser, to investigate the reproducibility of the results.

\section{RESULTS}

\section{Py-GC with programmed oven temperatures}

With temperature programming, Chromosorb 102 and 104 produced about 35 well-defined peaks with analysis times of around $60 \mathrm{~min}$. However, a further $30 \mathrm{~min}$ was required for the baseline to return fully to zero. With these phases, relatively tall, symmetrical and well-resolved peaks were produced. Chromosorb 101 and Tenax-GC produced rather fewer and less well-resolved peaks, and analysis times were even longer (Fig. 1). Chromosorb 103 and 105 separated only 15-20 peaks with relatively poor resolution. All the solid phases produced good baseline resolution in the early isothermal parts of the pyrograms, but later peaks were less well-resolved. If the oven temperature was raised above the final programmed temperature after the baseline had stabilized, further peaks could always be eluted.

As with Carbowax $20 \mathrm{M}$, on solid phases different organisms produced similar peaks which showed only small differences. Although Chromosorb 102 and 104 produced better peak resolution than Carbowax $20 \mathrm{M}$, they suffered from similar problems of very long analysis times and the appearance of spurious peaks due to the delayed elution of high boiling point products (French et al., 1980). Furthermore, all the solid phases were susceptible to column 'cracking' due to the differential expansion and shrinkage of the packing and the glass column during the temperature cycle. None of these solid phases appeared to offer significant advantages over Carbowax 20M when used with temperature programming.

\section{Py-GC with isothermal oven temperatures}

When Py-GC with Carbowax 20M was attempted at isothermal temperatures, a few poorly-resolved peaks were produced, unsuitable for microbial identification. However, with all the solid phases tested, an isothermal oven temperature of $100^{\circ} \mathrm{C}$ allowed the separation of 10-15 well-resolved peaks that appeared within $8 \mathrm{~min}$ (Chromosorb 103) to $25 \mathrm{~min}$ (Chromosorb 106). Most peaks were tall, symmetrical and baseline-resolved (Figs 2 and 3). The baseline had usually returned to zero within 20 to $40 \mathrm{~min}$, and further analyses could then be performed without the appearance of late-eluting spurious peaks.

Visual analysis showed that different organisms produced the same peaks which differed only quantitatively, but some of these differences were very marked (Figs 2 and 3). Retention time variation was insignificant, and individual peaks could easily be recognized by their shape and position. The two polystyrene phases, Poropak $\mathrm{Q}$ and Chromosorb 106, produced similar pyrograms but otherwise the different phases produced different patterns. Reproducibility was poor with Chromosorb 105 and this phase was not further examined. 

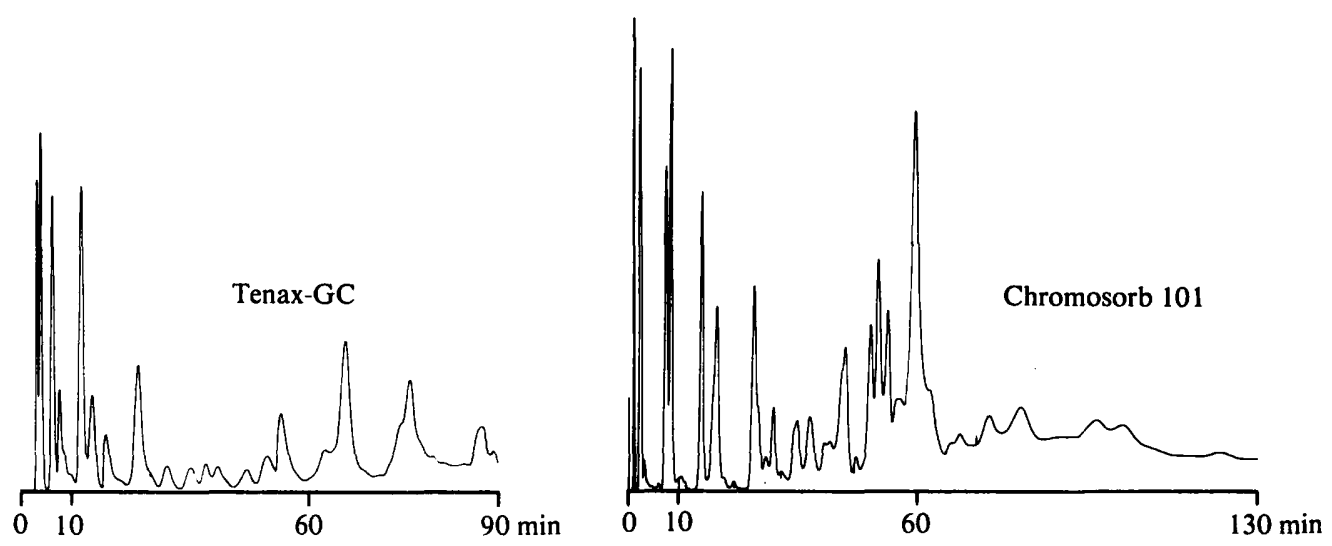

Fig. 1. Temperature-programmed Py-GC of $P$. aeruginosa with Tenax-GC and Chromosorb 101 columns. For conditions, see Methods.
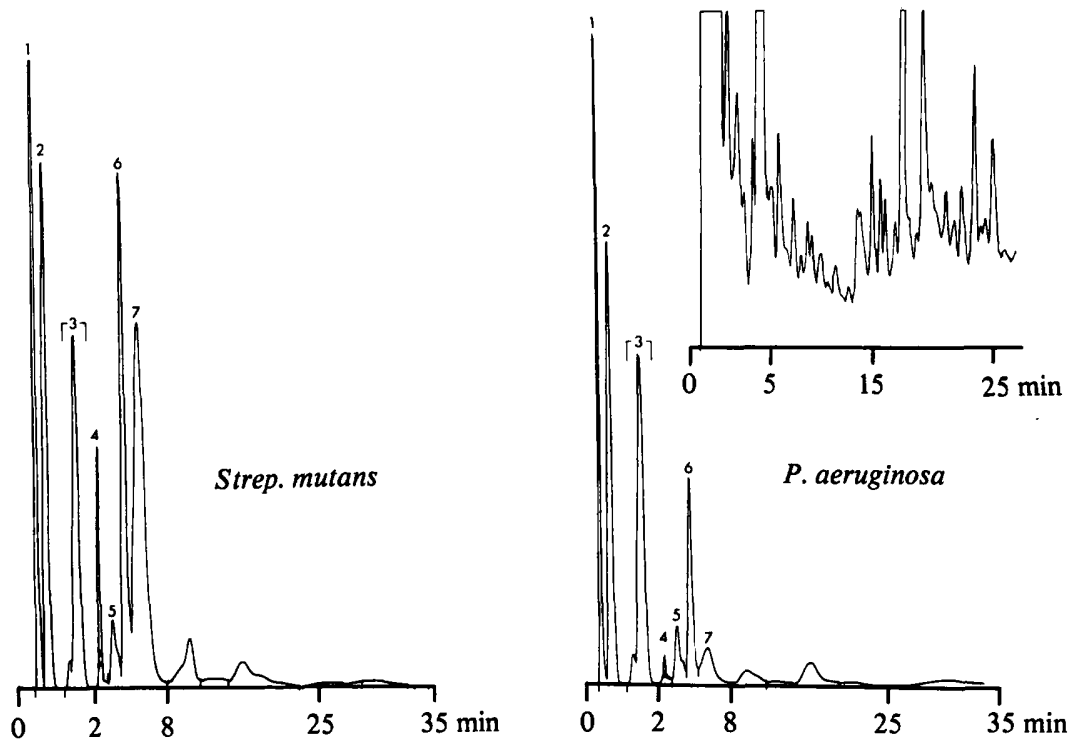

Fig. 2. Isothermal Py-GC of Strep. mutans and P. aeruginosa with Chromosorb 103 columns. (Inset: temperature-programmed Py-GC of $P$. aeruginosa with a Carbowax 20M column).

When each test organism was pyrolysed five times with each phase, the individual organisms were correctly identified when the data was analysed by orthogonal discriminant functions. The best discrimination was achieved with Chromosorb 104 (Fig. 4 and Table 1), but complete discrimination was also achieved in two dimensions with Chromosorb 103 (Fig. 5), Chromosorb 101 and Tenax-GC. Variation within organism groups is inversely related to discrimination and can be assessed by the scatter of the individual organism plots. Reproducibility (and hence discrimination) was significantly improved when normalized rather than uncorrected area percentage data were analysed.

The generalized (Mahalanobis) distance $\left(D^{2}\right)$ between the group centroids is a measure of the discrimination between organism groups (MacFie et al., 1978), and in our results was unrelated to orthodox taxonomic relationships. Thus, for Chromosorb 101, 102, 103 and 106, and Tenax-GC, E. coli and P. aeruginosa were closely related. With Chromosorb 106 and Poropak Q, Strep. mutans was close to K. aerogenes, while Staph. aureus, P. aeruginosa 

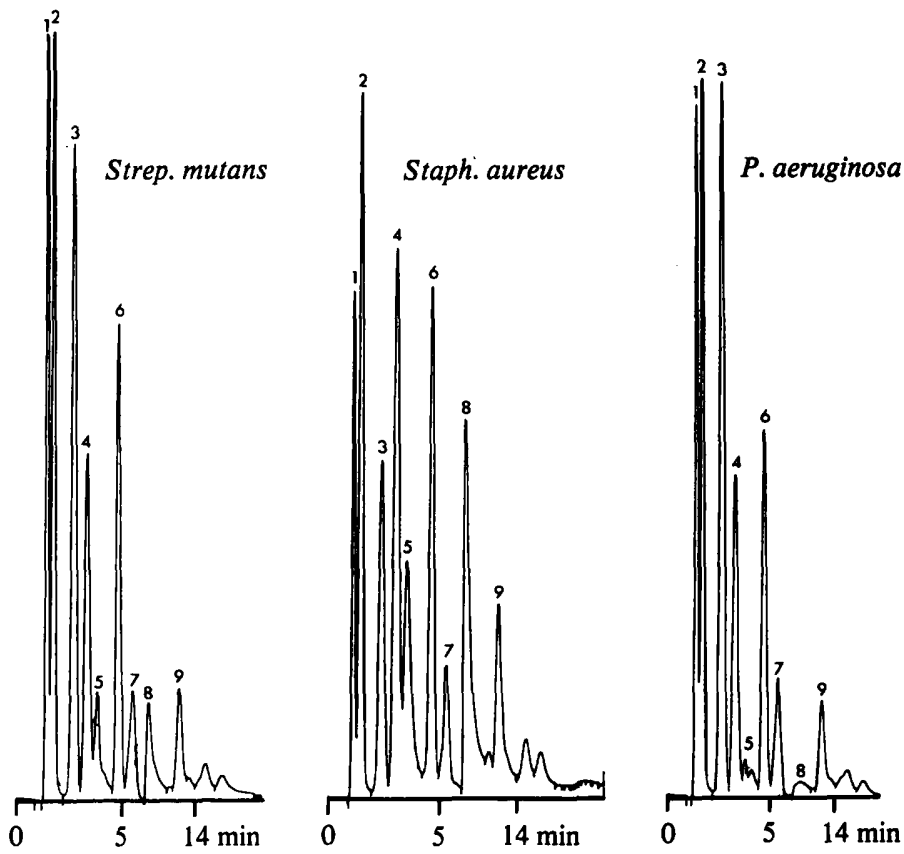

Fig. 3. Isothermal Py-GC of Strep. mutans, Staph. aureus and P. aeruginosa with Tenax-GC columns.

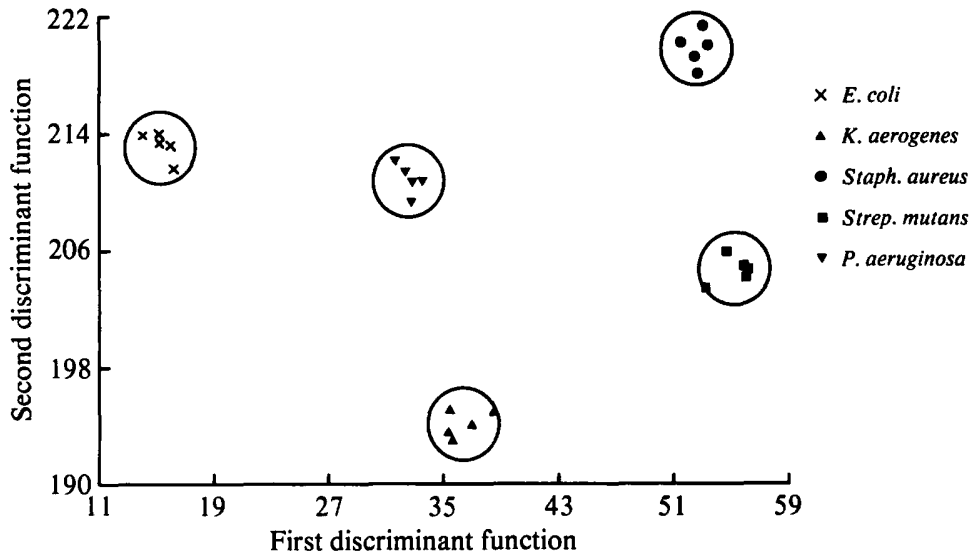

Fig. 4. Plot of the first two discriminant functions for isothermal Py-GC with Chromosorb 104. The circles represent $95 \%$ tolerance limits.

and $E$. coli were grouped together. Chromosorb 101 and 103 produced very similar patterns of discrimination, while those of Chromosorb 104 and Tenax-GC were rather different (Table 1). If more strains had been analysed it would have been possible to combine data from two or more phase types to improve discrimination further.

Pyrograms from all three pyrolyser/column combinations of Chromosorb 103 were visually similar, and peaks appeared at similar retention times. All the organisms examined with the new pyrolyser/column systems were correctly classified with the discriminant functions calculated from the original Chromosorb 103 data (Fig. 6). 


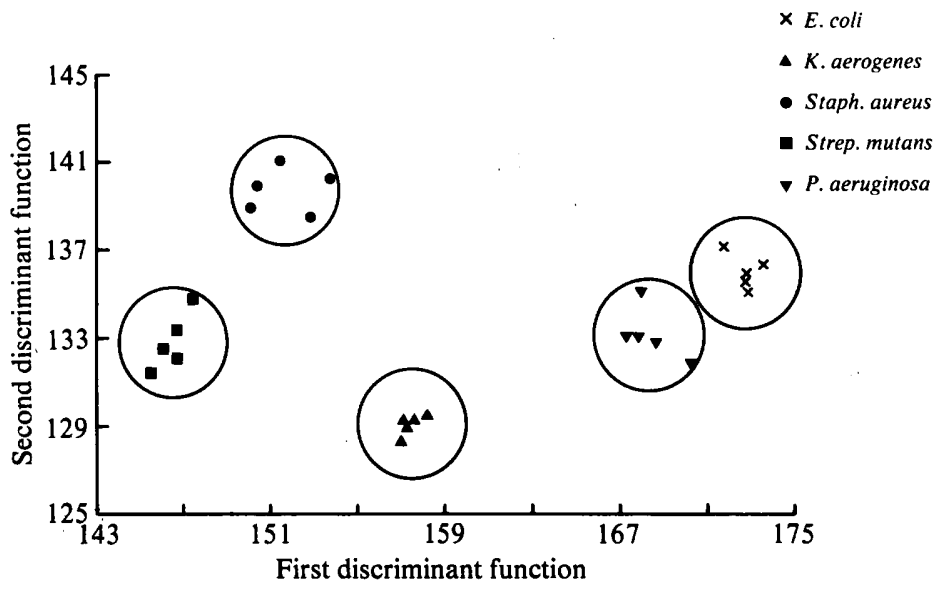

Fig. 5. Plot of the first two discriminant functions for isothermal Py-GC with Chromosorb 103.

Table 1. Generalized (Mahalanobis) distances between group centroids for four different stationary phases

\begin{tabular}{|c|c|c|c|c|c|c|}
\hline \multirow{2}{*}{$\begin{array}{l}\text { Stationary } \\
\text { phase }\end{array}$} & \multirow{2}{*}{$\begin{array}{l}\text { No. of } \\
\text { peaks }\end{array}$} & \multirow[b]{2}{*}{ Group*. } & \multicolumn{4}{|c|}{ Inter-group distances } \\
\hline & & & EC & KA & SA & SM \\
\hline Chromosorb 101 & 11 & $\begin{array}{l}\text { KA } \\
\text { SA } \\
\text { SM } \\
\text { PA }\end{array}$ & $\begin{array}{r}18 \cdot 3 \\
24 \cdot 6 \\
26 \cdot 6 \\
7.2\end{array}$ & $\begin{array}{r}0.0 \\
23.2 \\
17.9 \\
15.3\end{array}$ & $\begin{array}{r}0.0 \\
11.4 \\
19.3\end{array}$ & $\begin{array}{r}0.0 \\
20.9\end{array}$ \\
\hline Chromosorb 103 & 7 & $\begin{array}{l}\text { KA } \\
\text { SA } \\
\text { SM } \\
\text { PA }\end{array}$ & $\begin{array}{r}16.8 \\
21.3 \\
26.4 \\
5.2\end{array}$ & $\begin{array}{r}0.0 \\
12 \cdot 1 \\
11.7 \\
11.7\end{array}$ & $\begin{array}{r}0.0 \\
8.8 \\
17.9\end{array}$ & $\begin{array}{r}0.0 \\
21.9\end{array}$ \\
\hline Chromosorb 104 & 13 & $\begin{array}{l}\text { KA } \\
\text { SA } \\
\text { SM } \\
\text { PA }\end{array}$ & $\begin{array}{l}28.5 \\
37.9 \\
40.9 \\
20.2\end{array}$ & $\begin{array}{r}0.0 \\
30.2 \\
21.7 \\
19.2\end{array}$ & $\begin{array}{r}0.0 \\
15.2 \\
23.8\end{array}$ & $\begin{array}{r}0.0 \\
24.5\end{array}$ \\
\hline Tenax-GC & 9 & $\begin{array}{l}\text { KA } \\
\text { SA } \\
\text { SM } \\
\text { PA }\end{array}$ & $\begin{array}{r}14.2 \\
15.8 \\
22.3 \\
8.4\end{array}$ & $\begin{array}{r}0.0 \\
12.4 \\
12.4 \\
6.8\end{array}$ & $\begin{array}{r}0.0 \\
10.0 \\
11.1\end{array}$ & $\begin{array}{r}0.0 \\
15.3\end{array}$ \\
\hline
\end{tabular}

* EC, E. coli; KA, K. aerogenes; SA, Staph. aureus; SM, Strep. mutans; PA, P. aeruginosa.

Use of Chromosorb 103 for identification and subspeciation of strains of Strep. mutans

Nine different isolates of Strep. mutans were examined with the original Pye 204/ Chromosorb 103 combination. The original discriminant functions were applied to the peak area percentage values: six strains (including the reference NCTC 10449) were correctly identified as Strep. mutans with high probability. Three strains gave very different results, and Fig. 7 shows that these strains appeared to be different from any of the organisms previously examined. These aberrant strains were the reference strains FA-1, Z/AHT and B13.

\section{DISCUSSION}

With temperature programming, polymer solid phases offered little advantage over Carbowax 20M for Py-GC of micro-organisms, although peak resolution was improved, 


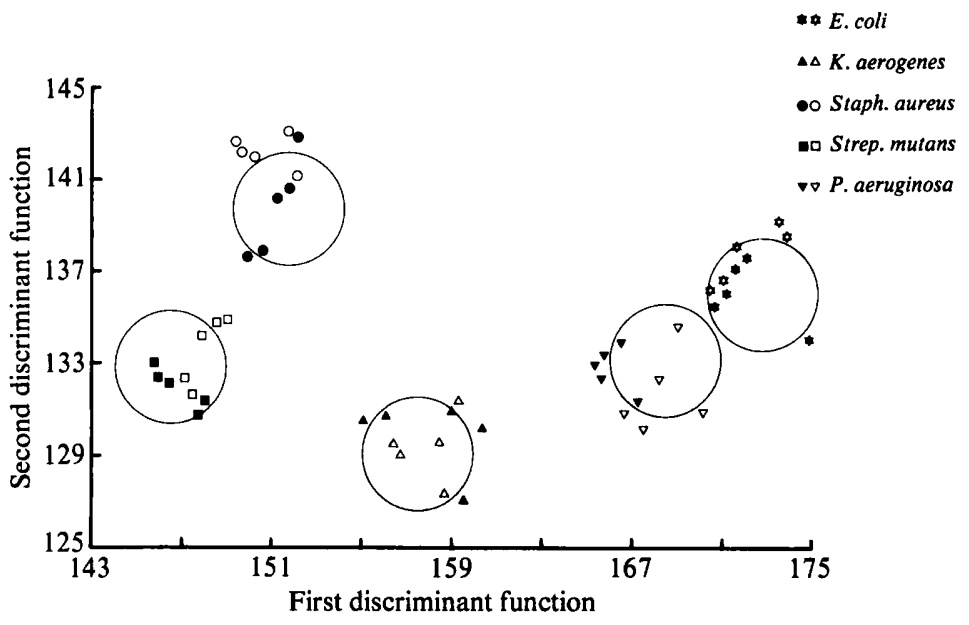

Fig. 6. Reproducibility of isothermal Py-GC with change of column or pyrolyser. The circles represent $95 \%$ tolerance limits of the first two discriminant functions obtained with the first pyrolyser and the first Chromosorb 103 column. The closed symbols represent discriminant function scores obtained with the first pyrolyser and the second Chromosorb 103 column: the open symbols represent the scores from the second pyrolyser and the first column.

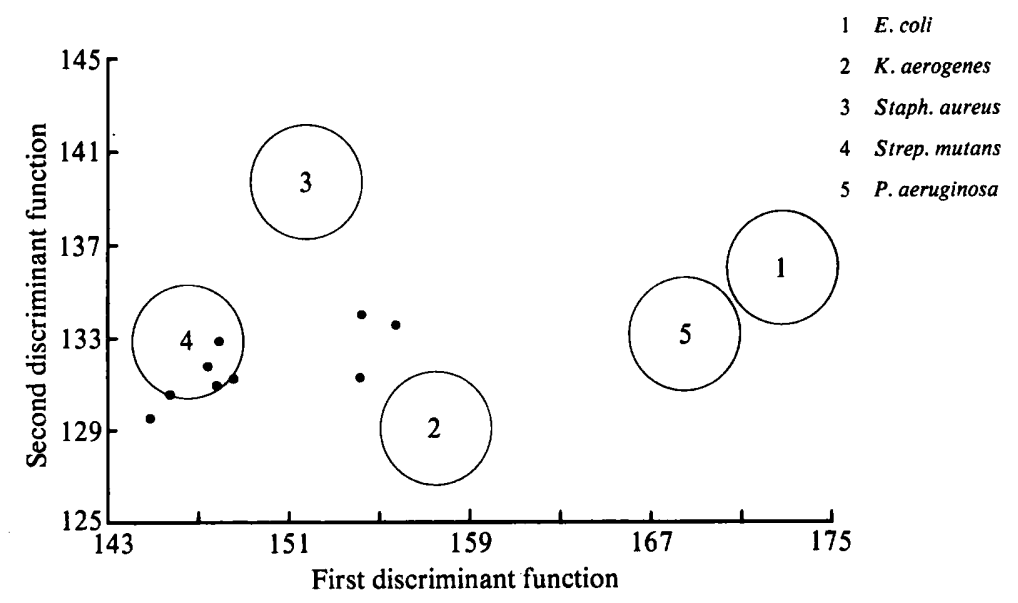

Fig. 7. Identification and subspeciation of Strep. mutans strains. The circles represent $95 \%$ tolerance limits of the first two discriminant functions for isothermal Py-GC of five genera obtained with Chromosorb 103. The symbols represent discriminant function scores for nine different isolates of Strep. mutans obtained with the same Py-GC system.

especially with Chromosorb 102 and 104 . However, at an isothermal oven temperature of $100{ }^{\circ} \mathrm{C}$, the use of solid stationary phases appeared to solve most of the problems we had previously encountered with Py-GC (French et al., 1980). Analysis times were short, and the main peaks of interest eluted within 8 to $25 \mathrm{~min}$, depending on the phase. Subsequently, the baseline showed only a slight variation and usually stabilized to zero within 20 to $40 \mathrm{~min}$. Because of the isothermal oven temperature, there was little danger of spurious peaks appearing in subsequent analyses. Shortening of analysis time was a major advantage of isothermal analysis, and since a balancing column was no longer required, a second pyrolyser/column combination could be installed in the same chromatograph oven. Analyses could be run sequentially on the two columns (both detector outputs being connected to the same integrator), so that while one column was being used for pyrolysis the other was allowed 
to stabilize. With this system four to six analyses per hour were possible with Chromosorb 103 compared with the five per day achieved with conventional temperature-programmed Carbowax 20M (Quinn, 1974).

The majority of peaks produced with isothermal solid phases were tall, narrow, symmetrical and baseline-resolved. This facilitated electronic integration and improved reproducibility. Later peaks tended to become rather broad-based, but area percentage values remained constant. With normalized data, pyrograms were reproducible on a second pyrolyser/column combination suggesting that inter-laboratory reproducibility is a real possibility.

The poor reproducibility of conventional Py-GC of micro-organisms has often been acknowledged, yet only rarely have microbiological controls been used (Stack et al., 1978). Added internal chemical markers have been used to adjust retention times and identify peaks (Hall \& Bennett, 1973; Sekhon \& Carmichael, 1975; Brosseau \& Carmichael, 1978), but we have not found this to be necessary with either Carbowax 20M or with solid phases. However, it is essential to include regular pyrolysis of a control organism, firstly to detect gross errors such as septum leakage, sample contamination or misplacement of the pyrolyser wire, and secondly to correct subsequent quantitative analyses for experimental variations in gas flow, detector sensitivity, column efficiency and growth media. Reproducibility, both within and between columns, was significantly improved by the use of a control organism for normalized peak area percentage calculations, and similar control methods would be essential for inter-laboratory reproducibility. Even with these adjustments, Py-GC is subject to a degree of experimental variation, probably resulting from slow elution of high boiling point products interfering with the quantitative analysis of subsequent pyrogram peaks. This is an inherent problem of Py-GC whatever analysis temperature is used, and therefore replicate analyses are advisable to reduce internal variation. For this purpose the relatively short analysis times of isothermal systems are essential.

Most previous workers have attempted to maximize the number of pyrogram peaks on the assumption that this would increase discrimination between species. To this end, the majority of studies have used temperature programming, and the use of the more efficient capillary columns has been strongly advocated (Levy \& Barney, 1968; Quinn, 1974; Needleman \& Stuchbery, 1977). However, the use of capillary columns has not been shown to improve microbial discrimination, and in most instances quantitative differences between pyrograms are obvious for only a few peaks. Furthermore, the analysis of large numbers of peaks is expensive in terms of computer time, and a data-reduction step is often employed to eliminate redundant peaks before final analysis. Our results with isothermal solid phase Py-GC indicate that good discrimination can be achieved between different genera with as few as seven peaks (Chromosorb 103). The number of peaks, and hence the degree of discrimination, may be increased by the combination of data from two different solid phases, and this may be necessary for species discrimination. The rapidity and reproducibility of these isothermal systems facilitates the selection of the most discriminant column or combination of columns for the particular organisms under investigation.

We do not know the identity of the pyrogram peaks, but they are presumably small molecules of high volatility. Identification of these molecules might facilitate the selection of isothermal gas chromatographic systems for optimal peak resolution and bacterial discrimination.

Discrimination between organisms such as Staph. aureus and $K$. aerogenes is easily achieved with simple orthodox tests, and the use of Py-GC is unnecessary for this purpose. However, we have subdivided isolates of Strep. mutans by Py-GC, and this method may be of practical value for the improvement of identification and subspeciation of groups of organisms which are poorly defined by orthodox bacteriological tests.

These results confirm that Py-GC can distinguish intra-species differences, that resemblance between pyrograms is not necessarily a measure of taxonomic similarity and that differences 
within species may be greater than between genera (Reiner \& Ewing, 1968; Sekhon \& Carmichael, 1975; Brosseau \& Carmichael, 1978; French et al., 1980). It is therefore necessary to examine relatively large numbers of strains to establish an adequate data base for microbial identification, and for this purpose the rapidity, reproducibility and stability of solid phases at isothermal temperatures are essential.

Work in progress indicates that these systems can differentiate between species and suggests that Py-GC may offer a practical contribution to routine microbial identification.

We are indebted to $\mathrm{Dr}$ C. S. Gutteridge and the Agricultural Research Council, Meat Research Institute, Langford for the generous loan of a Curie-point pyrolyser.

\section{REFERENCES}

Brosseau, J. D. \& Carmichael, J. W. (1978). Pyrolysis gas-liquid chromatography applied to a study of variation in Arthroderma tuberculatum. Mycopathologia 63, 67-79.

French, G. L., Gutteridge, C. S. \& Phillips, I. (1980). Pyrolysis gas chromatography of Pseudomonas and Acinetobacter species. Journal of Applied Bacteriology 49, 505-516.

GutTERIDGE, C. S. \& Norris, J. R. (1979). The application of pyrolysis techniques to the identification of micro-organisms. Journal of Applied Bacteriology 47, 5-43.

Hall, R. C. \& Bennett, G. W. (1973). Pyrolysis-gas chromatography of several cockroach species. Journal of Chromatographic Science 11, 439-443.

HEALY, M. J. R. (1973). Handling and interpreting multiple results. Proceedings of the Royal Society B 154, 369-374.

Hollis, O. L. (1966). Separation of gaseous mixtures using porous polyaromatic polymer beads. Analytical Chemistry 38, 309-316.

LEVY, R. L. \& BARNEY, J. E. (1968). High resolution and high sensitivity pyrolysis gas chromatography (PGC) for the identification of paints. In Proceedings of the 2nd National Symposium of Law Enforcement, Science and Technology, Chicago, pp. $325-331$.

MACFIE, H. J. H., GutTERIdGe, C. S. \& NorRis, J. R. (1978). Use of canonical variates analysis in differentiation of bacteria by pyrolysis gas-liquid chromatography. Journal of General Microbiology 104, 67-74.

May, R. W., Pearson, E. F., Porter, J. \& SCOTHERN, M. D. (1973). A reproducible pyrolysis gas-chromatographic system for the analysis of paints and plastics. Analyst 98, 364-371.

Needleman, W. \& Stuchbery, P. (1977). The identification of micro-organisms by pyrolysis gasliquid chromatography. In Analytical Pyrolysis, pp.
77-88. Edited by C. E. R. Jones \& C. A. Cramers. Amsterdam: Elsevier.

NiE, N. H., Hull, C. H., JenkiN, J. G., StennbrenNer, K. \& BeNT, D. H. (1975). Statistical Package for the Social Sciences. New York: McGraw-Hill.

Oxborrow, G. S., Fields, N. D. \& Puleo, J. R. (1976). Preparation of pure microbiological samples for pyrolysis gas-liquid chromatography studies. Applied and Environmental Microbiology 32, 306309.

Oxborrow, G. S., Fields, N. D. \& Puleo, J. R. $(1977 a)$. Pyrolysis gas chromatography of the genus Bacillus: effects of growth media on pyrochromatogram reproducibility. Applied and Environmental Microbiology 33, 865-870.

Oxborrow, G. S., Fields, N. D. \& Puleo, J. R. $(1977 b)$. Pyrolysis gas-liquid chromatography studies of the genus Bacillus. Effect of growth time on pyrochromatogram reproducibility. In Analytical Pyrolysis, pp. 69-76. Edited by C. E. R. Jones \& C. A. Cramers. Amsterdam: Elsevier.

QuinN, P. A. (1974). Development of high resolution pyrolysis-gas chromatography for the identification of micro-organisms. Journal of Chromatographic Science 12, 796-806.

REINER, E. \& EWING, W. H. (1968). Chemotaxonomic studies of some Gram-negative bacteria by means of pyrolysis-gas-liquid chromatography. Nature, London 217, 191-194.

Sekhon, A. S. \& Carmichael, J. W. (1975). Classification of some Gymnoascaceae by pyrolysisgas-liquid chromatography using added marker compounds. Sabouraudia 13, 83-88.

StaCK, M. V., Donoghue, H. D. \& TYleR, J. E. (1978). Discrimination between oral streptococci by pyrolysis gas-liquid chromatography. Applied and Environmental Microbiology 35, 45-50. 